Goldschmidt 2021 Abstract

https://doi.org/10.7185/gold2021.5873

\section{f-element sorption onto K-feldspar - A comprehensive characterization of mechanism and thermodynamics}

\author{
JULIA NEUMANN ${ }^{1}$, HANNES BRINKMANN ${ }^{1}$, SUSAN
} BRITZ $^{2}$, JOHANNES LUETZENKIRCHEN ${ }^{3}$, FRANK BOK ${ }^{4}$, MADLEN STOCKMANN ${ }^{5}$, VINZENZ BRENDLER ${ }^{6}$, THORSTEN STUMPF $^{7}$ AND MORITZ SCHMIDT ${ }^{8}$

${ }^{1}$ Helmholtz-Zentrum Dresden-Rossendorf

${ }^{2}$ GRS

${ }^{3} \mathrm{KIT}$

${ }^{4}$ Institute of Resource Ecology, Helmholtz-Zentrum DresdenRossendorf

${ }^{5}$ Helmholtz-Zentrum Dresden-Rossendorf, Research Site Leipzig

${ }^{6}$ Helmholtz-Zentrum Dresden-Rossendorf e.V. (HZDR)

${ }^{7}$ Helmholtz-Zentrum Dresden-Rossendorf, Institute of Resource Ecology

${ }^{8}$ Helmholtz-Zentrum Dresden - Rossendorf e. V. (HZDR)

Presenting Author: j.neumann@hzdr.de

The mobility of radionuclides in the environment, in particular in the context of a deep geological repository for radioactive waste, is heavily influenced by their interactions with charged mineral surfaces. This study investigates the retention potential of feldspars, a main component of granite as one potential host rock for a repository. The focus is on the sorption of trivalent actinides $(\mathrm{Am}, \mathrm{Cm})$ and their rare earth analogues $(\mathrm{Eu}, \mathrm{La}, \mathrm{Lu}$, $\mathrm{Nd}, \mathrm{Y}$ ) as a main source of radiotoxicity in spent nuclear fuel.

A multi-method approach was used, consisting of traditional batch sorption experiments over a broad range of experimental conditions to determine uptake. Generally, retention increases with increasing $\mathrm{pH}$ and reaches quantitative retention at near neutral conditions. Furthermore, a spectroscopic study of the sorption structure on the molecular level was conducted. Timeresolved laser-induced fluorescence spectroscopy (TRLFS) using the actinide $\mathrm{Cm}$ as a luminescent probe, shows that four surface complexes are formed, an inner sphere sorption complex and its two hydrolysis forms, as well as a ternary feldspar $/ \mathrm{Cm} /$ silicate complex at alkaline conditions $(\mathrm{pH}>10)$.

Based on the observed comprehensive batch sorption dataset a generic surface complexation model (SCM-A) was developed that describes sorption of trivalent actinides and their rare earth analogues as a function of a variety of geochemical parameters ( $\mathrm{pH}$, ionic strength, metal concentration, solid-liquid ratio,...). In a second step, the dataset for the model was further increased by taking the quantitative spectroscopic results into consideration (SCM-B).

The developed SCMs deliver surface complexation parameters of the formed sorption species, which are included in thermodynamic databases. This data is essential for the subsequent calculation of distribution coefficients in modern approaches like the Smart KD-concept[1] and reactive transport modeling. Therefore, this study provides a contribution to a more reliable safety assessment of repositories for radioactive waste. [2]

[1] Stockmann, M. et al., "Smart Kd-values, their uncertainties and sensitivities - Applying a new approach for realistic distribution coefficients in geochemical modeling of complex systems", Chemosphere., 187, 277-285 (2017).

[2] Neumann, J. et al., "A comprehensive study of the sorption mechanism and thermodynamics of f-element sorption onto $\mathrm{K}$ feldspar", J. Colloid Interface Sci. (2020). https://doi.org/10.1016/j.jcis.2020.11.041.

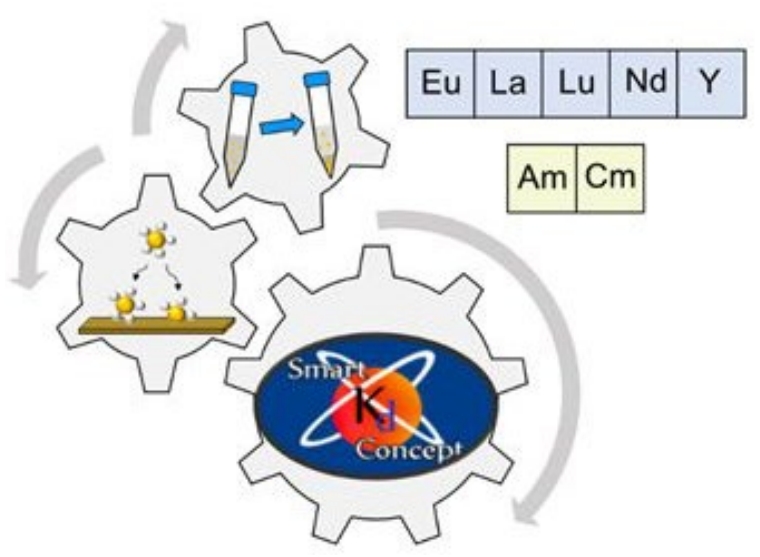

